\title{
RBEP
}

\section{Sexualidade e deficiência intelectual: um curso de capacitação para professores}

Paloma Pegolo de Albuquerque

Maria Amélia Almeida

\section{Resumo}

Professores da educação especial costumam enfrentar dificuldades em sala de aula com a questão da sexualidade. O objetivo deste estudo foi planejar, aplicar e avaliar um programa de intervenção (curso) para 21 professores de jovens com deficiência intelectual de uma escola especial em uma cidade do interior de São Paulo. O curso durou dois meses e teve caráter teórico e prático, com discussões, dinâmicas de grupo, atividades de role-playing e de resolução de problemas, filmes e também uma atividade prática em sala de aula. Por meio de uma avaliação sobre o curso e de entrevistas, perceberam-se algumas mudanças na forma de os professores interagirem com os alunos quando o tema era a sexualidade, além de reflexões sobre a questão e revisão de sua postura como educadores sexuais.

Palavras-chave: educação especial; deficiência intelectual; sexualidade; capacitação de professores. 


\section{Abstract}

Sexuality and intellectual disabilities: a training course for teachers

Special education teachers often face difficulties in the classroom with the issue of sexuality. The aim of this study was to plan, implement and evaluate an intervention program (course) for 21 teachers of young people with intellectual disabilities from a special school in a town in the interior of the State of São Paulo. The course has lasted two months and has got a theoretical and practical aspect, with discussions, group dynamics, roleplaying and problem solving activities, movies and also a practical activity in the classroom. By means of an evaluation of the course and interviews, we noticed changes in the way teachers interact with students when the topic was sexuality, reflections on the issue, and review of teachers position as sex educators.

Keywords: special education; intellectual disability; sexuality; teachers training.

\section{Introdução}

Atualmente, a perspectiva da inclusão social exige uma nova postura diante da pessoa com deficiência intelectual, considerando suas potencialidades e resgatando seus direitos. A inclusão é mais do que a inserção de pessoas com deficiência na sociedade, é uma postura de aceitação e respeito pelas diferenças. Refere-se à oportunidade de vivência plena em diversos contextos - escolar, familiar, mercado de trabalho, lazer - e deve acontecer em todos os âmbitos, dando as mesmas oportunidades às pessoas com deficiência, permitindo um acesso irrestrito a todas as instituições e aos papéis sociais. Isso inclui também a oportunidade de vivenciar a sexualidade.

A sexualidade vai além dos aspectos biológicos e genitais e não se resume simplesmente ao ato sexual. De acordo com Denari (2002), referese às formas de sentir, pensar e agir, que são aspectos imprescindíveis ao entendimento do ser humano em todas as suas dimensões. Pode-se entender, portanto, sexualidade como amor, afetividade, busca de prazer e também genitalidade, como afirmam Dias et al. (1995), situando-a sempre no contexto do relacionamento, do prazer e da responsabilidade (Glat, Freitas, 2002).

Em vários âmbitos da sociedade, há dificuldade para falar e lidar com a questão da sexualidade, apesar dos avanços existentes com o passar do tempo. Segundo Chauí (1985), o sexo é encarado por diferentes sociedades como algo complicado e perigoso. Assim, há diferentes formas de 
se lidar com o tema: por meio da educação sexual, do silêncio e da não orientação ou da repressão.

A sexualidade é um tema polêmico que desperta dificuldades àqueles que cotidianamente se defrontam com essa questão, como os professores, por exemplo. Quando são professores de jovens com deficiência intelectual, o desafio parece ser ainda maior, como mostram diversas pesquisas (Dall'Alba, 1992; Denari, 2002; Glat, Freitas, 2002; Giulio (2003); Maia, Aranha, 2005; Plunkett et al., 2002; Ribeiro, Nepomuceno, 1992).

Segundo França Ribeiro (2001), os professores não estão tendo a preparação necessária para atuarem na área da sexualidade humana e nem sempre têm consciência de que, mesmo sem a realização de nenhuma atividade específica, estão atuando como educadores sexuais. No mesmo sentido, Figueiró (2004, p. 124) afirma que "a sexualidade é uma das questões que mais tem trazido dificuldades, problemas e desafios aos educadores, no seu trabalho cotidiano de ensinar".

De acordo com os estudos de Giami (2004), nota-se que mesmo os profissionais não estão imunes a crenças inadequadas acerca da sexualidade e da deficiência. A percepção de muitos profissionais sobre a sexualidade de seus alunos se alterna: por um lado, eles são considerados sexualmente infantis ou assexuados e, por outro, sexualmente agressivos e sem controle. O estereótipo da pessoa com deficiência como sexualmente agressiva ou assexuada é uma extensão da visão popular do deficiente como um ser "demoníaco" ou "eterna criança". O autor ainda coloca que, apesar das diferentes crenças, há um fundamento único, que é a negação da sexualidade.

O funcionamento intelectual subnormal não significa que as pessoas com deficiência intelectual não são capazes de ter uma conduta sexual compatível com exigências sociais, elas podem, sim, aprender a exprimir seu desejo de forma socialmente aceita, desde que sejam orientadas dentro de seu nível cognitivo, de maneira que possam assimilar os conhecimentos (Glat, Freitas, 2002; Gherpelli, 1995; Facion, 1990).

O que muitas vezes falta aos jovens com deficiência intelectual é um processo efetivo de educação/orientação sexual. Se eles não recebem essas orientações adequadas, acabam tendo poucas oportunidades para aprendê-las de fontes usuais, pois as pessoas com deficiência geralmente não têm as mesmas chances para descobrir sobre sexualidade com seus pares, falar livremente com os amigos sobre sexo e acabam não podendo aprender sobre um aspecto vital do desenvolvimento (Behi, Behi, 1987).

A própria autora percebeu, em entrevistas realizadas anteriormente com a população de professores de jovens com deficiência intelectual, muitas dificuldades relacionadas à questão da sexualidade, como o não reconhecimento das necessidades e dos desejos sexuais e afetivos desses jovens; crenças inadequadas e preconceitos acerca do tema, que influenciavam a prática docente; ausência de orientação dada aos alunos devido à dificuldade de dialogar sobre a questão; e confusão quanto ao papel de orientadores sexuais. 
Diversos estudos com professores e profissionais que trabalham com pessoas com deficiência intelectual apontam para a importância de programas de intervenção em orientação sexual para essa população, pois parecem existir, ainda, dificuldades nessa área. São necessárias novas investigações que apontem as dificuldades específicas e as possíveis falhas no sistema de formação desses profissionais.

Glat (2005) aponta que tanto as escolas regulares quanto as instituições e as escolas especiais têm que considerar a orientação sexual como prioridade programática. Ainda se faz necessário, segundo a autora, a realização de estudos e investigações mais amplas referentes ao desenvolvimento de programas de orientação dos jovens e de suas famílias. Denari (1997) complementa ao afirmar que há necessidade de orientação às famílias e à instituição quanto à forma de lidar com a sexualidade do adolescente com deficiência intelectual, algo também recomendado por Maia (2006, p. 243): "para que a orientação sexual oferecida aos alunos seja efetiva, é necessário oferecê-la antes aos profissionais e à família e refletir sobre seus objetivos".

Diante dessas necessidades apontadas pela literatura e pela vivência da própria pesquisadora, julgou-se importante a realização de um programa de intervenção relacionado ao tema, buscando-se a capacitação docente por meio do maior preparo e de informação para lidar com os alunos e, assim, incentivando o desenvolvimento global desses indivíduos.

O objetivo deste trabalho foi planejar, aplicar e avaliar um programa de intervenção sobre orientação sexual (curso) para professores de jovens com deficiência intelectual.

\section{Curso Sexualidade e deficiência intelectual}

Participaram do curso 21 professores de jovens com deficiência intelectual. Apenas um dos participantes era do sexo masculino, e a média de idade entre eles era de 39,9 anos. Em relação ao tempo em que trabalhavam na instituição, a média foi de 10,6 anos.

O estudo foi realizado numa escola especial de uma cidade de médio porte do interior de São Paulo, sendo utilizado um auditório para a realização do curso. A escola atende pessoas com deficiência intelectual e outros tipos de deficiências relacionadas e possuía, na época, 482 alunos e 65 professores.

Inicialmente, foram realizadas entrevistas com os professores, utilizando-se um roteiro elaborado pela própria pesquisadora e um termo de consentimento esclarecido. Os temas abordados sobre as atitudes em relação à sexualidade foram: mídia; local para se discutir/trabalhar a sexualidade; necessidades/desejos sexuais de pessoas com deficiência intelectual; namoro, casamento e paternidade/maternidade na deficiência intelectual; e facilidade ou não para falar sobre sexualidade. Já os temas relacionados à forma de lidar com a orientação sexual dos alunos foram: conversa sobre sexualidade; perguntas sobre sexualidade; interesses 
sexuais; manifestação sexual; dificuldades e problemas relacionados à sexualidade; masturbação; namoro; casamento; prática de sexo; informações; educação/orientação sexual; papel na orientação sexual; e a última questão propunha aos entrevistados que complementassem as informações, caso quisessem.

Todas as entrevistas foram gravadas e posteriormente transcritas pela pesquisadora para o levantamento das necessidades dos participantes. Partiu-se das principais carências e dificuldades dos entrevistados para a montagem do curso e o estabelecimento de prioridades relativas ao seu conteúdo.

O curso foi realizado por meio de encontros semanais com duração de duas horas cada um, resultando em oito encontros (16 horas de duração, dois meses ao todo). Os encontros tiveram uma parte teórica - exposição feita pela pesquisadora - e momentos para se trabalhar as dificuldades e necessidades relatadas pelos participantes, por meio de discussões, dinâmicas, atividades de role-playing e de resolução de problemas, filmes e outras.

No primeiro dia, o tema tratado foi "O que é sexualidade" e os objetivos foram: debater sobre alguns conceitos relacionados à sexualidade; refletir sobre o tema e sua importância em nosso dia a dia; desmitificar alguns tabus ligados à sexualidade, situando-a num contexto mais amplo de relacionamento entre os seres humanos; abordar a sexualidade como um aspecto natural e positivo da vida; e dar uma visão histórica e social dessa questão. Inicialmente, foi feito um contrato de sigilo com os participantes e uma dinâmica de apresentação, passando para uma explanação teórica feita pela pesquisadora. Em seguida, houve um exercício de reflexão, no qual foi pedido que os participantes relatassem sobre a orientação sexual que receberam quando eram adolescentes.

O segundo encontro - "Sexualidade e deficiência intelectual" - teve como objetivos discutir o conceito de deficiência intelectual, debater a sexualidade na deficiência intelectual e desmitificar alguns mitos que circundam a questão. Foi realizada uma dinâmica, na qual os participantes escreviam seus medos, anseios e preocupações acerca da sexualidade de pessoas com deficiência intelectual. Em seguida, esses papéis eram sorteados e lidos em voz alta, relatando-se como se sentiam em relação ao conteúdo. Posteriormente, deu-se a explanação teórica da pesquisadora.

O terceiro encontro - "O papel da família, da escola e da sociedade frente à sexualidade de pessoas com deficiência intelectual" - teve como objetivos explicitar os papéis da escola, da família e da sociedade no processo de educação/orientação sexual das pessoas com deficiência intelectual; dar parâmetros de como se comportar em situações diversas relacionadas à tomada de decisões na educação dos alunos; e refletir sobre a influência das agências sociais sobre o comportamento e as atitudes sexuais das pessoas. Além da explanação teórica feita pela pesquisadora, houve uma atividade de role-playing relacionada ao tema da sexualidade, na qual os participantes deveriam encenar uma situação envolvendo professor e aluno. 
O quarto encontro - "Educação e orientação sexual de pessoas com deficiência intelectual" -, que teve como objetivos discutir a importância da orientação sexual para as pessoas com deficiência intelectual e apresentar propostas de conteúdo de programas de orientação sexual, contou com a explanação teórica da pesquisadora e a realização de uma dinâmica de continuação de histórias. Essa dinâmica consistia na divisão dos participantes em dois grupos, cada participante escrevia o início de uma história sobre a sexualidade na deficiência intelectual, até a pesquisadora pedir para pararem, quando trocavam os papéis e davam continuidade à história de outra pessoa. Ao final, as histórias foram lidas e comentadas.

Já o quinto encontro - "Comportamentos sexuais considerados inadequados" - teve como objetivos citar os principais comportamentos sexuais considerados inadequados; debater a funcionalidade desses comportamentos; dar exemplos de como lidar com eles; e levar os participantes a refletirem sobre como podem agir diante dessas situações. Nesse dia, foi realizada uma atividade de reflexão sobre um exemplo de comportamento sexual inadequado, solicitando-se que os participantes respondessem a questões sobre uma situação descrita. A atividade foi retomada e discutida após a explanação teórica da pesquisadora.

O sexto encontro - "Relacionamentos amorosos de pessoas com deficiência intelectual" - teve como objetivos refletir sobre os prós e os contras dos relacionamentos amorosos de pessoas com deficiência intelectual e dar parâmetros de comportamento de como os participantes podem agir diante de situações novas com os alunos. Além da explanação teórica feita pela pesquisadora, foi realizada uma dinâmica sobre opiniões opostas, na qual os participantes foram divididos em dois grupos e foram apresentadas duas situações (casamento e paternidade), solicitando-se que cada grupo assumisse a postura de ser favorável a uma das situações e contra a outra. Eles deveriam escrever três argumentos e tentar convencer os integrantes do outro grupo, seguindo-se um debate.

O sétimo encontro - "Relacionamentos amorosos de pessoas com deficiência intelectual II" - buscou aprofundar a discussão sobre os relacionamentos amorosos, revisando outros aspectos tratados no curso, exemplificando, por meio de recursos audiovisuais (televisão, aparelho de DVD, filmes), situações relacionadas ao tema. Na ocasião, foram apresentados recortes de dois filmes sobre namoro, casamento e paternidade de pessoas com deficiência intelectual e, posteriormente, houve uma discussão sobre os filmes.

O último encontro - "Sexualidade e deficiência intelectual: revisão, dúvidas e encerramento" - teve como objetivos avaliar os conhecimentos adquiridos pelos participantes no curso; debater e tirar dúvidas ainda existentes; e refletir sobre os principais aspectos tratados durante o curso. Houve uma revisão de todo o conteúdo anterior e, antes do encerramento, foi entregue aos participantes um questionário de avaliação sobre o curso, que continha seis perguntas descritivas e tinha o objetivo de levantar a opinião dos participantes sobre os encontros, os aspectos positivos e os negativos, bem como sugestões e/ou críticas. 
A respeito da metodologia dos encontros, foi realizada uma exposição teórica pela pesquisadora todos os dias, exceto nos dois últimos, destinados à apresentação de filmes e às dúvidas/esclarecimentos. Para tanto, foram utilizados um retroprojetor e transparências, com o objetivo de tornar a exposição mais atraente e organizada. Essa metodologia foi julgada interessante porque economiza tempo e proporciona reflexão e trabalho em grupo, incentivando a empatia e a identificação.

Por outro lado, foram feitas diversas dinâmicas em grupo e atividades práticas, algo que foi elogiado pelos participantes e parece ter sido muito positivo. O objetivo de tais atividades era que os participantes refletissem sobre tudo aquilo que já havia sido discutido e aplicassem esses saberes em situações práticas, ajudando a resolver problemas. Além disso, notouse que esse tipo de atividade incentivava a participação, havendo muitos relatos de experiência.

Em todos os encontros, foram entregues resumos de uma página com as informações principais discutidas na semana anterior, para atualizar aqueles que não haviam comparecido e também servir como revisão a todos, formando-se uma cartilha sobre sexualidade e deficiência intelectual ao final do curso.

Ao longo dos encontros, foram distribuídos ainda muitos textos sobre diversos temas, como deficiência intelectual; sexualidade; sexualidade na deficiência intelectual; influência da mídia sobre a sexualidade; pais e a sexualidade; superproteção; escola; adolescência; limites; metodologia para educação/orientação sexual; masturbação; e aspectos biológicos da reprodução. Acredita-se que tais materiais tenham sido úteis para os professores, pois isso foi exteriorizado por muitos deles.

Foram sorteados e entregues brindes ao final de cada encontro, com o objetivo de incentivar a participação dos presentes. Os brindes foram basicamente livrinhos infantis de uma coleção sobre sexualidade, assim como um livro da área de educação especial.

Ao final de todos os encontros, ocorria sempre um momento de confraternização, com o oferecimento de bebidas e comidas aos presentes. Essa estratégia foi tomada por acreditar-se que momentos de lazer são importantes para o estreitamento dos laços e a realização de conversas informais, o que pode também ter sido um incentivo a mais para a participação dos convidados.

\section{Atividade em classe sobre sexualidade}

Com o objetivo de levar os professores a refletirem sobre problemas e situações específicas de seu cotidiano, assim como contribuir com seu processo formativo, foi proposto que os docentes realizassem uma atividade relacionada à orientação sexual em sala de aula com seus alunos e entregassem um relatório escrito descrevendo como havia sido a experiência.

Para isso, foi discutida durante o curso a importância de trabalhos de orientação sexual para jovens com deficiência intelectual e apresentadas 
propostas de conteúdo para programas de orientação sexual, enfatizandose alguns exemplos do que poderia ser trabalhado com os alunos na sala de aula, as metodologias utilizadas e os cuidados necessários nesse processo, tendo como objetivo geral o desenvolvimento saudável da sexualidade (Suplicy et al., 1994; Tepper, 2001; Assumpção Júnior, Sprovieri, 2005; Giulio, 2003; Glat, Freitas, 2002; Glat 2005).

Ao final do curso, 14 professores entregaram seus relatórios, demonstrando que realizaram atividades nas quais discutiram a sexualidade em sala de aula, sendo que quatro deles aproveitaram dúvidas dos alunos para iniciar o debate. Os temas das discussões foram: namoro, diferenças entre os sexos feminino e masculino e dúvidas gerais sobre sexualidade.

Pôde-se perceber que muitos professores estavam lidando de forma interessante com o tema da sexualidade: "iniciei a atividade colocando para os alunos que conversaríamos sobre um tema muito importante, sexualidade (...) deixei bem claro que falar sobre tal assunto não era errado e sim necessário e que gostaria que eles aproveitassem o máximo para tirar todas as dúvidas" (Professora 2$)^{1}$ e "no desenvolvimento da aula me preocupei em falar sobre o assunto sexualidade em um sistema que fosse facilmente compreendido pelos alunos" (Professora 20).

Alguns utilizaram recursos, como uma coleção de livros sobre sexualidade voltados às crianças e aos adolescentes; revistas para recortes de figuras; folhas para desenho; figuras de homens e mulheres; e dois bonecos de pano confeccionados pela própria professora, um feminino e outro masculino.

A maioria dos professores escreveu em seus relatórios que houve reação de interesse pelas atividades por parte dos alunos, com apresentação de dúvidas e perguntas. Os temas dessas perguntas foram variados, como doenças sexualmente transmissíveis; de que maneira ocorre a gravidez; desejos sexuais; nome dos órgãos genitais; possíveis malefícios da masturbação; utilidade da camisinha; e parto.

Foram citados também por seis professoras relatos espontâneos de experiência por parte dos alunos durante as atividades, nos quais contaram situações que viveram relacionadas à sexualidade, como demonstra a Professora 2: "naquela conversa que a gente teve todo mundo falou o que queria, viram os livros, eles viram que não é uma coisa que é proibida, né, ficou mais natural (...) coisas que antes eram faladas meio com medo e agora estão falando mais naturalmente".

Uma das professoras, inclusive, realizou quatro atividades de forma contínua e relatou progressos no comportamento dos alunos, pois na primeira atividade eles escreveram suas dúvidas em papéis sem identificação e, no decorrer das semanas, passaram a perguntar diretamente para a professora, gerando um clima acolhedor na sala de aula para debates acerca dos mais diferentes temas.

As atividades realizadas em classe pelos professores parecem ter

${ }^{1}$ Serão utilizados números para resguardar a identidade dos professores. sido muito proveitosas, pois, além de ser um primeiro passo em direção à implantação da orientação sexual na escola (para muitos, essa foi 
a primeira vez que conversaram sobre sexualidade com seus alunos), consistiram num esforço desses professores em aplicar os ensinamentos e as discussões do curso em suas realidades.

Isso está de acordo com Figueiró (2004), que afirma ser o professor a figura indicada para deflagrar a orientação sexual na escola, por ele ser da instituição e conhecer suas carências e potencialidades. Porém, a autora alerta que para que os professores se apropriem dessa função é importante receberem formação continuada, processo no qual o professor vai repensar e refletir sobre sua prática pedagógica, que precisa ter ligação com problemas e situações específicas que eles enfrentam em sua sala de aula: "penso que muitos necessitam vivenciar a prática pedagógica supervisionada do ensino da sexualidade para fortalecerem, em si próprios, a atitude de reconhecimento e aceitação de que a Educação Sexual é função da escola" (Figueiró, 2004, p. 140).

\section{Principais efeitos da intervenção}

Após três meses, foram feitas entrevistas na própria escola com cada um dos participantes do curso, contendo questões sobre suas atitudes em relação à sexualidade e como lidavam com a orientação sexual dada aos alunos. As entrevistas foram gravadas e transcritas. Além disso, o questionário final sobre o curso, preenchido pelos participantes no último encontro, foi analisado.

Os dados obtidos foram ordenados e agrupados conforme núcleos de sentido comuns e transformados em categorias de análise, seguindo-se a técnica de análise de conteúdos de Bardin (1977). Foram realizadas análises qualitativas por meio da percepção da pesquisadora sobre as etapas da pesquisa, das atividades advindas da intervenção e principalmente da discussão com a literatura.

A avaliação geral foi favorável na maior parte dos encontros, e podese perceber que muitos participantes relataram terem gostado do curso: "muito bom e deveria se estender a todos que de forma direta ou indireta trabalhem com pessoas especiais" (Professora 21). Foram sugeridos por diversos professores novos trabalhos na instituição para discutir assuntos importantes relacionados ao cotidiano escolar, como demonstram as verbalizações seguintes: "pelo tema ser muito abrangente e no decorrer do tempo ocorrerem fatos que nos trazem dúvidas e dificuldades, outros encontros como estes deveriam ocorrer" (Professora 21) e "deveríamos ter mais participação de grupos de pesquisa na escola" (Professora 15).

Percebeu-se que muitos professores tiveram benefícios com a participação no curso e apresentam agora mais condições para lidar com a sexualidade em sala de aula, como explicita a Professora 13: "os alunos gostaram da aula e foram bem participativos, e sempre que surgirem dúvidas estarei informando e ensinando adequadamente".

Diversas questões foram consideradas aspectos positivos pelos professores, como o enriquecimento teórico: "tem coisas que você passou 
que esclareceu as dúvidas, ajuda a gente até a ficar mais solta para falar com eles" (Professora 9) e "não tivemos determinadas orientações que nós estamos tendo agora e isso foi positivo para que a gente aprendesse também para poder passar para as crianças" (Professora 3).

Da mesma forma, Plunkett et al. (2002) perceberam um aumento do grau de conhecimento sobre sexualidade e deficiência de cuidadores de pessoas com deficiência intelectual após frequentarem um programa de educação sexual.

Foi percebida também a troca de experiências e de ideias entre os professores participantes do curso: "às vezes você vê um problema dentro da sua sala que o outro professor conseguiu resolver de outra maneira, você pega aquela ideia" (Professora 2); assim como a abertura de um espaço para se trabalhar a sexualidade: "deixou que o professor pode sim conversar, que é uma coisa natural! Acho que deixou a gente mais aliviado!" (Professora 2); e a ajuda no cotidiano da escola.

Foram apresentados diversos aspectos que podem sugerir mudanças na forma de encarar e de lidar com a sexualidade na deficiência intelectual, como a mudança de visão sobre a sexualidade e da forma de encará-la (mais naturalidade): "consigo encarar com mais naturalidade determinados assuntos em sala de aula, coisa que antes me descabelava só de pensar" (Professora 19). Muitos professores passaram a apresentar uma mudança de reação perante as manifestações sexuais por parte dos alunos, pois antes apresentavam uma postura de punição ou omissão e passaram a orientar: "observei melhor os problemas que os alunos apresentaram e procurei solucionar através de conversas e orientações" (Professora 1).

Também foram notadas a quebra de tabus e a perda do medo e da timidez de trabalhar com o tema da sexualidade: "acho que já quebrou um pouco aquele tabu que a gente tem de não querer falar, de se sentir envergonhada! (...) aprender a lidar com essas questões sem preconceitos" (Professora 15) e "me sinto mais segura em trabalhar com as questões em sala de aula" (Professora 16); assim como a visualização da possibilidade do estabelecimento de relacionamentos afetivos e amorosos na deficiência intelectual: "eles têm todos os direitos, tanto quanto a gente" (Professora 12).

Outros aspectos que sugerem mudanças foram o despertar para o tema da sexualidade e a atenção às manifestações dos alunos relacionadas: "eu não reparava tanto nesses pitis do E.; ${ }^{2}$ depois que eu comecei a fazer o curso eu comecei a reparar que era uma necessidade que ele tem que não consegue se expressar, eu comecei a enxergar o E.!" (Professora 12).

Destacam-se alguns professores que anteriormente haviam afirmado não conversarem com seus alunos sobre sexualidade e relataram na entrevista final que passaram a conversar, como demonstra a Professora 1: "antigamente, eu falava quando eu tinha chance, às vezes tinha algo que passava; agora não, eu não deixo passar, eu aproveito o embalo, então agora eu presto mais atenção para aproveitar mais".

Além disso, também aumentou o número de professores afirmando U uso da inicial E. é para pre-
servar a identidade do aluno. que depois do curso seus alunos estavam fazendo perguntas sobre 
sexualidade. Isso está de acordo com Figueiró (2004), que afirmou ser a manifestação da sexualidade dos alunos no espaço escolar cada vez mais comum, e eles, direta ou indiretamente, demonstram aos professores que precisam e desejam ouvir e falar sobre sexo.

Outra indicação de mudança foi o despertar do professor para seu papel na educação e orientação sexual dos alunos, pois muitos professores afirmaram que antes do curso preferiam fazer encaminhamentos de seus alunos a outros profissionais: "eu não ficava abordando, só quando me perguntavam, mas hoje em dia, com a conversa, eu vi que existe a necessidade de se falar, não dá para deixar para o outro, é necessário que eu mesma faça alguma coisa" (Professora 11).

Por fim, foi destacado o aumento do preparo para lidar com situações que surgem em sala de aula relacionadas à sexualidade: "teve esse meu aluno, foi depois do curso, dele vir me perguntar, estava beijando a menina, estava sentindo algumas coisas, se era normal; e se não fosse o curso eu não iria saber responder para ele" (Professora 18).

Essas mudanças estão de acordo com as descritas na literatura. Brantlinger (1983), após realizar um workshop sobre sexualidade e deficiência para pessoas próximas a indivíduos com deficiência intelectual, como pais e profissionais, percebeu que o treinamento, apesar de suas limitações, foi efetivo para produzir mudanças de atitudes nessas pessoas, de forma que elas passaram a aceitar melhor a sexualidade na deficiência intelectual.

Figueiró (2004) também realizou um trabalho de formação de orientadores sexuais com professores e percebeu que houve valorização profissional e percepção de mudanças nas pequenas atitudes destas educadoras, estando mais dispostas a agirem frente à temática da sexualidade.

De forma geral, apesar de diversos ganhos advindos do curso "Sexualidade e deficiência intelectual" e do fato de os professores terem tido uma chance de debater temas e refletir sobre suas práticas educativas, muitos ainda permanecem inseguros e apresentam medos relacionados ao tema da sexualidade. Isso se reflete na forma de lidar com a questão. Ainda se mostra presente, embora em menor intensidade, o medo dos professores de enfrentarem a escola e a família de seus alunos, caso discutam a sexualidade em sala de aula, como explicita a Professora 17 ao referir-se a sua atividade em classe: "houve interesse dos alunos quando comecei a falar com eles, mas sinto dificuldade, não por vergonha, mas por insegurança, com medo de falar alguma coisa que os pais ou a escola pudessem ir contra".

Pode ser que esses medos sejam uma "desculpa" para não assumirem responsabilidades, talvez até porque eles já se sintam sobrecarregados por suas atividades, desvalorizados e despreparados. Isso já foi observado por vários autores, como Dall'Alba (1992), Ribeiro (2001), Freitas (1996) e Maia e Aranha (2005), os quais constataram que os professores de pessoas com deficiência intelectual não recebem uma formação completa que possibilite a eles tornarem-se orientadores sexuais adequados. 
Também foram encontradas algumas dificuldades na realização do curso, como as faltas (a média de participantes nos encontros foi de 12,8) e as desistências, o que gerou uma certa instabilidade no grupo e dificuldade para programação de atividades que exigiam um número mínimo de pessoas para serem bem sucedidas. Essas faltas podem indicar algumas hipóteses e reflexões, como o fato de os professores não considerarem a sexualidade dos alunos algo importante, preferindo ignorá-la e continuar tratando os alunos como eternas crianças, conforme apontam Giami (2004) e Glat e Freitas (2002), entre outros.

Parece haver uma dificuldade específica de alguns participantes em lidar com o tema da sexualidade, independentemente de estar associado com a questão da deficiência intelectual, o que pode complicar a participação deles em um curso desse feitio.

Pode-se considerar, a partir da reduzida presença, um provável medo dos participantes em estabelecer mudanças em suas formas de educar. Alguns podem preferir continuar agindo do mesmo jeito porque mudar exige sacrifícios, autoanálise e revisão da própria postura. Alguns professores estão há mais de 30 anos na instituição e não mudaram suas práticas pedagógicas.

Essas dificuldades já foram apontadas na literatura, como demonstra Figueiró (2004), que também percebeu, ao final do seu trabalho feito com professores, que poucos continuaram realizando projetos formais e sistematizados em suas salas de aula, o que demonstra a complexidade de implantação de programas de orientação sexual nas escolas de forma isolada.

\section{Algumas conclusões}

Mediante as verbalizações informais dos participantes, a impressão da pesquisadora, a análise da avaliação sobre o curso e as entrevistas, percebeu-se que a participação no grupo fez com que os professores refletissem sobre a questão da sexualidade na deficiência intelectual e, especificamente, sobre seus alunos, e isso os levou a uma revisão de sua postura como educadores sexuais. Perceberam-se algumas mudanças entre os professores na forma de interagir com os alunos quando o tema era a sexualidade, sendo que alguns passaram a implementar discussões regulares em sala de aula sobre a questão.

De todas as indicações de mudanças, em geral, os professores parecem ter adquirido uma maior compreensão da complexidade da questão da sexualidade e de sua importância na vida das pessoas com deficiência intelectual, com uma atenção e respeito maior por seus interesses sexuais e afetivos. Há indícios de um aumento da segurança e do preparo para lidar com o tema e de um questionamento do papel de docente frente a esse processo. Esses aspectos reunidos parecem refletir na melhoria da disposição dos professores frente às demandas dos alunos em sala de aula, como foi percebido, por exemplo, pelo aumento 
de diálogo professor-aluno e das perguntas referentes à sexualidade por parte dos jovens. Além disso, foram percebidas algumas mudanças de comportamento referentes à orientação sexual, como o aumento do diálogo sobre sexualidade.

Entretanto, todas as dificuldades dos professores apresentadas anteriormente - principalmente a dificuldade de preparação dos alunos para uma vivência inclusiva na sociedade, em relação à sexualidade levam em consideração que somente um curso parece pouco para mudar a rotina dos professores no que se refere tanto a suas opiniões sobre a sexualidade na deficiência intelectual quanto às atitudes e, principalmente, aos comportamentos de orientação sexual. Como aponta Werebe (1998), a orientação sexual não é uma panaceia e não irá resolver todos os problemas daqueles que a recebem, ela é sim um primeiro passo na implantação de mudanças reais e consistentes.

Isso demonstra que o fato de ter dificuldades em falar sobre sexo é algo que não muda só com a participação em um curso, pois ele garante principalmente a informação teórica, mas a mudança de comportamento é algo que envolve diversas variáveis, como a educação sexual recebida ao longo da vida e os valores pessoais. De acordo com Figueiró (2004), o professor, como indivíduo, carrega consigo inseguranças, dúvidas, desconhecimentos, tabus e medos, frutos de sua própria história e educação sexual precária. E tudo isso influenciará a facilidade ou não para abordar a questão da sexualidade, a predisposição para imprimir mudanças nos comportamentos de orientação sexual e até na persistência frente às dificuldades desse processo.

Recomenda-se que exista um trabalho permanente em relação à sexualidade nas escolas especiais, mas isso só será possível com algumas condições. Em primeiro lugar, preparação dos professores para lidarem com esse tema desde a formação básica. Em segundo, que a escola dê condições a esse trabalho, por exemplo, inserindo o tema no planejamento das aulas, oferecendo treinamentos/cursos aos professores e demais funcionários e, o mais importante, abrindo um espaço permanente de debate sobre sexualidade, mudando, assim, o clima escolar.

Trata-se de considerar a questão sob o ponto de vista preventivo e não remediativo, como tem acontecido até então no cenário escolar ao tentar evitar-se que os alunos tomem contato com o tema da sexualidade e vivam segregados das oportunidades de relacionamento amoroso e sexual e, assim, não apresentem "problemas". Isso lembra a afirmação de Glat (2005) de que na maior parte das escolas brasileiras não existem programas de orientação e educação sexual para jovens com deficiência; e, quando há, geralmente são trabalhos esporádicos, pontuais e não preventivos, surgindo a partir de algum problema na instituição.

Todas as condições que foram citadas anteriormente dariam aos professores mais segurança para abordar com propriedade os tópicos relacionados à sexualidade em sala de aula, cumprindo seu papel de educadores no sentido mais amplo, que é o de preparar os alunos para a vida em sociedade. 


\section{Referências bibliográficas}

ASSUMPÇÃO JÚNIOR, F. B.; SPROVIERI, M. H. S. Deficiência mental: sexualidade e família. Barueri: Manole, 2005.

BARDIN, L. Análise de conteúdo. São Paulo: Edições 70, 1977.

BEHI, R.; BEHI, E. E. Sexuality and mental handicap. Nursing Times, v. 83, n. 43, p. 50-53, 1987.

BRANTLINGER, E. Measuring variation and change in attitudes of residential care staff toward the sexuality of mentally retarded persons. Mental retardation, v. 21, n. 1, p. 17-22, 1983.

CHAUÍ, M. Repressão sexual: essa nossa (des)conhecida. 9. ed. São Paulo: Brasiliense, 1985.

DALL'ALBA, L. Sexualidade e deficiência mental: concepção do professor. 1992. Dissertação (Mestrado em Educação Especial) Universidade Federal de São Carlos, São Carlos, 1992.

DENARI, F. E. O adolescente especial e a sexualidade: nem anjo, nem fera. 1997. Tese (Doutorado em Educação) - Universidade Federal de São Carlos, São Carlos, 1997.

DENARI, F. E. Sexualidade e deficiência mental: reflexões sobre conceitos. Revista Brasileira de Educação Especial, Marília, v. 8, n. 1, p. 9-14, 2002 .

DIAS, T. R. S. et al. Deficiência mental e sexualidade: a perspectiva de mães de deficientes. Integração, Brasília, v. 6, n. 15, 1995.

FACION, J. R. A sexualidade nas doenças mentais infanto-juvenis. Integração, Brasília, v. 3, n. 6, p. 5-7, 1990.

FIGUEIRÓ, M. N. D. O professor como educador sexual: interligando formação e atuação profissional. In: RIBEIRO, P. R. M. (Org.).

Sexualidade e Educação: aproximações necessárias. São Paulo: Arte e Ciência, 2004.

FREITAS, M. R. Concepções de profissionais sobre a importância de uma proposta de educação sexual para deficientes mentais. 1996. Dissertação (Mestrado em Educação Especial) - Universidade Federal de São Carlos, São Carlos, 1996.

GHERPELLI, M. H. B. V. Diferente, mas não desigual: a sexualidade no deficiente mental. São Paulo: Gente, 1995. 
GIAMI, A. O anjo e a fera: sexualidade, deficiência mental, instituição.

São Paulo: Casa do Psicólogo, 2004.

GIULIO, G. D. Sexuality and people living with physical or developmental disabilities: a review of key issues. The Canadian Journal of Human Sexuality, East York, v. 12, n. 1, 2003.

GLAT, R. Desarrollo psicosocial y sexualidad de jóvenes portadores de deficiencias. In: CASTILLA, M. E.; FREQUEST, A.; GRZONA, M. A. (Eds.). Educación Especial: otras miradas. Mendoza, Argentina: Facultad de Educación Elemental y Especial de la Universidad Nacional de Cuyo, 2005. p. 5-14 (Construir, desconstruir, reconstruir, v. 2). Disponible en: $<$ http://www.eduinclusivapesq-uerj.pro.br/livros_artigos/ listagem_artigos.asp?page $=4>$.

GLAT, R.; FREITAS, R. C. de. Sexualidade e deficiência mental: pesquisando, refletindo e debatendo sobre o tema. Rio de Janeiro: Sette Letras, 2002.

MAIA, A. C. B. Sexualidade e deficiências. São Paulo: Unesp, 2006.

MAIA, A. C. B.; ARANHA, M. S. F. Relatos de professores sobre manifestações sexuais de alunos com deficiência no contexto escola. Interação em Psicologia, v. 9, n. 1, p. 103-116, 2005.

PLUNKETT, S. W. et al.; STACEYLEE, L.; NEAL, R. A.; SANCHEZ, M. G. An evaluation of a community-based sexuality education program for individuals with developmental disabilities. Eletronic Journal of Human Sexuality, v. 5, 2002. Disponível em: <www.ejhs.org. Acesso em: 20 mar. 2005.

RIBEIRO, H. C. da França. Sexualidade e os portadores de deficiência mental. Revista Brasileira de Educação Especial, Marília, v. 7, n. 2, 2001.

RIBEIRO, P. R. M.; NEPOMUCENO, D. M. Sexualidade e deficiência mental: um estudo sobre o comportamento sexual do adolescente excepcional institucionalizado. Jornal Brasileiro de Psiquiatria, v. 41, n. 4, p. 167-170, 1992.

SUPLICY, M. et al. Guia de orientação sexual: diretrizes e metodologia. 2 ed. São Paulo: Casa do Psicólogo, 1994.

TEPPER, M. S. Becoming sexually able: education to help youth with disabilities. Siecus Report, v. 29, n. 3, p. 5-13, 2001.

WEREBE, M. J. G. Sexualidade, política e educação. Campinas: Autores Associados, 1998. 
Paloma Pegolo de Albuquerque, doutoranda em Psicologia pela Universidade Federal de São Carlos (UFSCar), trabalha com os temas: bullying escolar, deficiência intelectual e sexualidade.

palomanier@yahoo.com.br

Maria Amélia Almeida, doutora em Educação Especial, é docente nos cursos de Psicologia e Educação Especial da Universidade Federal de São Carlos (Ufscar), atuando também como docente/pesquisadora do Programa de Pós-Graduação em Educação Especial dessa universidade.

ameliama@terra.com.br

Recebido em 26 de agosto de 2009.

Aprovado em 15 de abril de 2010. 